\title{
112 - Teaching and Training Old Age Psychiatry around the world
}

\section{Proposed by: Horacio Firmino \& Carlos Augusto de Mendonça Lima}

\section{Summary:}

In response to the global challenges of population aging in the World, it is crucial to improve research, education and clinical training in old age in order to meet the growing demands placed on

psychogeriatric care services.

An overview is provided on the status of old age psychology and psychiatry, and other health professionals, as part of the multidisciplinary care delivery system for the elderly in the World. Available educational offerings and clinical training in geriatric mental health and geriatrics at both undergraduate and postgraduate level are described.

Important issues raised include the need for more educational and clinical training programs for specialists, a broader commitment to aging research and the need to increase interest in working with older adults among students across disciplines at the medical, psychological and education faculties and hospitals.

This educational initiative must focus not only on the transmission of knowledge on aging-related topics, but also on the training of specific skills and competencies.

An effective intervention in psychogeriatrics should involve a strategy with the participation of a multidimensional network that includes the commitment of researchers, educators, clinicians, health policy-makers and older adults.

Several recommendations to improve educational strategies concerning late life mental health care are presented to promote discussion, and develop new educational strategies.

\section{Presenters:}

Horácio Firmino - Advances at educational at the curriculum of the new Psychiatrists and other mental health professionals at Portugal

Carlos A. de Mendonça Lima- The WPA survey on Teaching and Training in Old Age Psychiatry: 20012018

Manuel Sanchez Perez - Mental Health Educational Reality at Spain

Manuel Teixeira Verissimo - Geriatrics New or Old discipline- educational perspectives of Europe and the reality of Portugal 